\title{
Cement-based additive manufacturing: experimental investigation of process quality
}

\author{
Panagis Foteinopoulos ${ }^{1} \cdot$ Vivien Esnault ${ }^{2} \cdot$ George Komineas $^{1} \cdot$ Alexios Papacharalampopoulos $^{1}$. \\ Panagiotis Stavropoulos ${ }^{1}$
}

Received: 7 August 2019 / Accepted: 22 January 2020 / Published online: 28January 2020

(C) The Author(s) 2020

\begin{abstract}
The interest in additive manufacturing (AM) of cement-based materials is steadily increasing. Moreover, there is a growing need for higher productivity and part quality. In this study, the impact of the different values of the process parameters on part quality was identified. An alternative process-control strategy was investigated, according to which the width of the extruded path is controlled by the ratio of the extrusion speed over the scanner head speed. To conduct linear- and rotational-extrusion experiments, an experimental apparatus was designed. The significance of the effect of the speed ratio on the part quality was found to be the highest, followed by the extrusion radius, whereas the extrusion speed appeared to be of low importance. Therefore, in linear extrusion, high quality and consistency can be achieved by maintaining the ratio value above 0.8 . However, in rotational extrusion, the effect of the radius was additionally considered by calculating the ratio on the outer side of the part, rather than on the centerline. Thus, acceptable quality and consistency were ensured for both linear and curved paths by controlling the aforementioned ratio values.
\end{abstract}

Keywords Additive manufacturing $\cdot$ Experimental $\cdot$ Empirical modeling $\cdot$ Process parameters $\cdot$ Concrete

\section{Introduction}

The construction sector accounts for almost $10 \%$ of the European gross domestic product (GDP) [1], and several European organisms and platforms aim to increase its innovation and efficiency [2]. The implementation of additive manufacturing (AM) is an important step toward achieving this purpose [3, 4]. AM is the process of using 3D model data to join materials, typically layer upon layer [5], for the production of objects. It allows the manufacturing of complex geometries with near-zero material waste; moreover, AM is applicable to a variety of materials, thus offering increased design freedom [6,7]. The interest in AM has been steadily increasing in the last years [8]: it has been estimated that

Panagiotis Stavropoulos

pstavr@1ms.mech.upatras.gr

1 Department of Mechanical Engineering and Aeronautics, Laboratory for Manufacturing Systems and Automation (LMS), University of Patras, Patras, Greece

2 Lafarge Holcim Research and Development, Lyon, France globally, the use of AM exclusively accounts for an added value of $\$ 667$ million [9], a fact that is very encouraging concerning new ideas and adaptations of AM in other sectors. Liang et al. [10] highlighted the advantages of cement-based AM applications by using examples from 3D-printed buildings in China.

A large number of different AM processes are currently available [11]; these processes vary in terms of their process mechanism, the manner that the layers are deposited, and the materials that can be used $[5,12]$. The vast majority of the existing studies and applications referring to cement-based AM [13] utilize a modified form of material extrusion; the use of AM processes other than cement-based ones is scarce [14]. Cement-based AM differs in three major aspects from AM applications in which other materials are used: the process mechanism, the materials, and the scale. The process mechanism is not thermal-based, as in the majority of AM applications [7]. The material properties and the difference of two orders of magnitude in scale (nozzle diameter, layer height) significantly affect the phenomena that take place. The application of cement-based AM requires studies that are focused on more efficient process parameter calibration and 


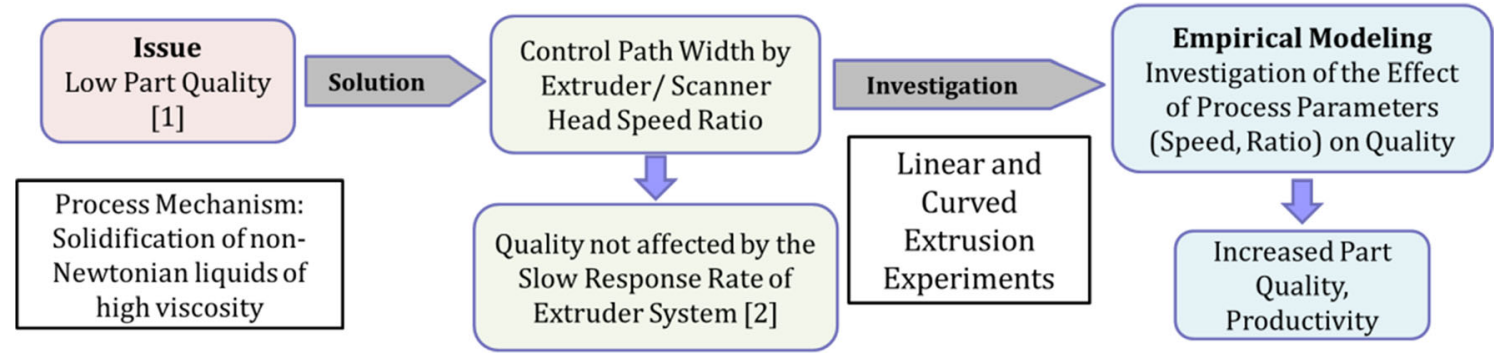

Fig. 1 Application of the proposed approach to address important issues in cement-based AM

machine control. However, owing to the fact that AM for concrete-based materials for the construction sector is a rather new application, relevant studies are quite limited [13].

Most studies on cement-based AM and other AM applications for the construction sector have been focused on material-related issues. Such a representative study is that of Le et al. [15]; they studied the effects of different dosages of material components on the resulting shear strength. Moreover, they correlated the workability and open time of the final material to the aforementioned material dosages. Gosselin et al. [16] presented a procedure that enabled the modification of the material properties of the mix as it moved toward the nozzle. The same technique was investigated by Esnault et al. [17]; in their study, a special viscosity-increasing additive was injected to the mix before it would reach the nozzle. This technique improved the printability of the concrete materials, while simultaneously allowing them to retain their cohesion, which is an important challenge in cementbased AM [10].

Another group of studies has been focused on the development of AM machines. Hinczewski et al. [18] developed a stereolithography-based AM application for ceramic materials, which was used for the study of the effects of each material component. The AM machine developed by Khoshnevis et al. [19] was based on the contour crafting process; also, the influence of the design parameters on the product quality was investigated. Lim et al. [20] developed an automated concrete AM machine that was used for the investigation of material parameters and design aspects.

Studies focusing on other issues also exist, such as that of Salte et al. [21], in which the effects of the design, printing, and assembly on the structure of the final product were studied. In [22], how the tensile bond strength of printed mortar is affected by various process parameters was investigated. However, in cement-based AM, one of the crucial issues that needs to be addressed through research studies is that of higher precision and productivity [23]. Nevertheless, there is a shortage of studies focusing on such process-related issues.

In this work, the effects on quality of controlling the path width were investigated, using an alternative control strategy. The path width was controlled by changing the scanner head speed, while maintaining the extrusion speed (material flow) constant. This led to a change in the ratio of the aforementioned speeds, thus affecting the width of the deposited path. The advantage of this approach is its higher precision and productivity because the response time of the scanner head is faster than that of the extrusion head-system for largescale cement-based AM applications [24] (Fig. 1). Furthermore, the effect of important process parameters on the part quality were studied; these process parameters were the extrusion speed, the ratio of the extrusion/scanner head speed, and the radius under which the extrusion takes place. Moreover, linear- and curved-extrusion experiments were conducted utilizing a small-scale experimental setup that had been designed and constructed in-house.

\section{Approach}

Two types of experiments were conducted: linear and curved extrusion. The selection of the process parameters, the key performance indicator (KPI), their levels, and the design of the experiments will be described in this section.

The process parameters that were selected for the linearextrusion experiments were the extrusion speed and the ratio of the extrusion/scanner head speeds. The first process parameter was selected because it is currently used for the control of the material flow in most AM applications. The second process parameter was chosen in order to define the range of

Table 1 Detailed range of values of the PCQM

\begin{tabular}{ll}
\hline PCQM level & Part characteristic \\
\hline 1 & Lack of continuity (holes, cavities) \\
& Variation of width $>40 \%$ \\
& Uneven surfaces \\
& Variation of width $>25 \%$ \\
& Mild inconsistencies, relatively even surfaces \\
& Variation of width $15-25 \%$ \\
3 & Minor inconsistencies, even surfaces \\
& Variation of width $<15 \%$ \\
4 & Smooth and even parts, no inconsistencies \\
& Variation of width $<5 \%$ \\
\hline
\end{tabular}




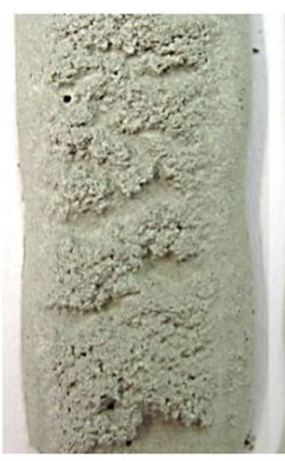

$\mathrm{PCQM}=1$

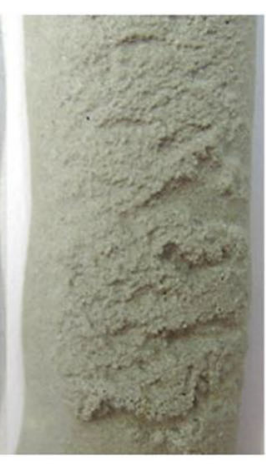

PCQM $=2$

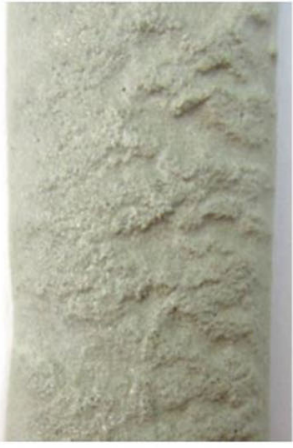

$\mathrm{PCQM}=3$

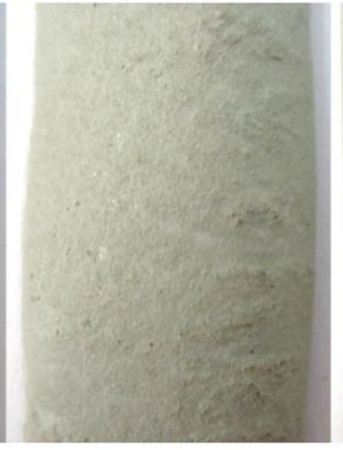

$\mathrm{PCQM}=4$

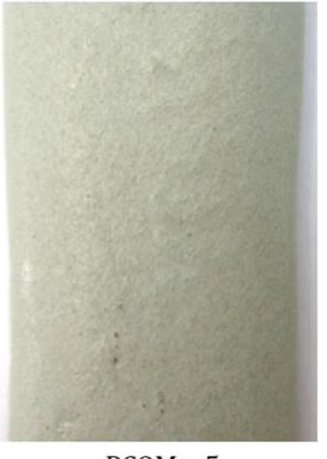

$\mathrm{PCQM}=5$

Fig. 2 Test parts of different PCQM levels. Levels 1 and 2: not acceptable; level 3: barely acceptable; levels 4 and 5: acceptable

values that maintain the quality of the resulting parts. The process parameters used in the curved-extrusion experiments were the ratio of the extrusion/scanner head speeds and the radius under which the extrusion would take place. The extrusion/scanner head speeds, which will be hereafter referred to as ratio, are calculated via the following equation:

Ratio $=\frac{v_{\mathrm{ex}}}{v}$

where $v_{\mathrm{ex}}$ is the speed of the material when exiting the nozzle of the extruder, which will be referred to as extrusion speed, and $v$ is the speed of the scanner head of the machine.

The levels of the process parameters of the linear experiment were selected in order to identify the ratio range that would lead to the production of successful parts. Smaller intervals were employed between the levels of the process parameter for the ratio in the range that was within the expected critical ratio threshold (i.e., levels 1, 2, and 3). Larger intervals were employed between levels 4 and 5 . The rotational experiments were conducted using the ratio range that yielded successful linear parts in order to determine the significance of the effect of curvature. The behavior of the fresh concrete paste was viscous [25]; consequently, it had certain relaxation times [26]. In order to accurately capture a linear, a KohlrauschWilliams-Watts (KWW), or even non-linear behavior [26], five different levels were used for the material extrusion variable [27-30].

The KPI that was used as the response factor was the part consistency-quality metric (PCQM). The PCQM is a

Table 2 Linear experiments: factor levels and values

\begin{tabular}{lllllll}
\hline Factor & Name (unit) & \multicolumn{2}{l}{ Level } & & & \\
\cline { 3 - 7 } & & 1 & 2 & 3 & 4 & 5 \\
\hline $\mathrm{A}$ & $\begin{array}{c}\text { Extrusion/conveyor } \\
\text { ratio } \\
\text { Extrusion speed } \\
(\mathrm{mm} / \mathrm{s})\end{array}$ & $0.55-0.6$ & $0.65-0.7$ & $0.8-0.85$ & 1.2 & 2 \\
$\mathrm{~B}$ & 12 & 15 & 18 & 30 & 40 \\
\hline
\end{tabular}

qualitative empirical metric, reflecting the consistency and quality of the extruded part. The higher the value of this metric is, the better the quality and the consistency of the extruded test part is. Five levels were used for the PCQM: levels 4 and 5 corresponded to high-quality parts, level 3 to acceptable ones, whereas levels 1 and 2 could be considered as non-acceptable. More specifically, level 1 has been used for parts that showed lack of continuity, such as holes and cavities, or a width variation of more than $40 \%$ along their length. Level 2 has been used for parts that might be continuous, but that had an uneven surface and a width variation along their length was within the range of $25-40 \%$. Level 3 has been used for parts that had a width variation of $15-20 \%$, featuring some mild inconsistencies and uneven surfaces. Finally, levels 4 and 5 for parts that were even in their width, with smooth and consistent surfaces. More details can be found in Table 1.

Test parts that presented lack of cohesion and continuity, as well as width inconsistencies and very uneven surfaces, have been characterized as non-acceptable. The reason for this was that a multilayer part consisting of layers with the aforementioned characteristics would be of low quality, or would even fail, owing to its poor dimensional accuracy, very uneven surface, and low mechanical properties, especially in the case of transverse loads. Images of the test parts (ribbons) of different PCQM levels can be seen in Fig. 2.

Tables 2 and 3 list the process parameters, which are the factors of the linear and the rotational experiments, as well as their corresponding levels and their values.

Owing to the fact that two factors were used in each experiment, an exhaustive combination is required according to the

Table 3 Rotational experiments: factor levels and values

\begin{tabular}{llccc}
\hline Factor & Name (unit) & \multicolumn{2}{l}{ Level } \\
\cline { 3 - 5 } & & 1 & 2 & 3 \\
\hline A & Extrusion/rotary table ratio & $0.75-0.80$ & $0.95-1.00$ & $1.2-1.25$ \\
B & Extrusion radius (mm) & 50 & 100 & 200 \\
\hline
\end{tabular}


Table 4 Factor-level combinations for the linear experiments

\begin{tabular}{|c|c|c|}
\hline Experiment no. & $\begin{array}{l}\text { Factor A: } \\
\text { extrusion/conveyor } \\
\text { ratio (level) }\end{array}$ & $\begin{array}{l}\text { Factor B: } \\
\text { extrusion } \\
\text { speed (level) }\end{array}$ \\
\hline 1 & 1 & 1 \\
\hline 2 & 1 & 2 \\
\hline 3 & 1 & 3 \\
\hline 4 & 1 & 4 \\
\hline 5 & 1 & 5 \\
\hline 6 & 2 & 1 \\
\hline 7 & 2 & 2 \\
\hline 8 & 2 & 3 \\
\hline 9 & 2 & 4 \\
\hline 10 & 2 & 5 \\
\hline 11 & 3 & 1 \\
\hline 12 & 3 & 2 \\
\hline 13 & 3 & 3 \\
\hline 14 & 3 & 4 \\
\hline 15 & 3 & 5 \\
\hline 16 & 4 & 1 \\
\hline 17 & 4 & 2 \\
\hline 18 & 4 & 3 \\
\hline 19 & 4 & 4 \\
\hline 20 & 4 & 5 \\
\hline 21 & 5 & 1 \\
\hline 22 & 5 & 2 \\
\hline 23 & 5 & 3 \\
\hline 24 & 5 & 4 \\
\hline 25 & 5 & 5 \\
\hline
\end{tabular}

Taguchi factor analysis [31]. Consequently, 25 linear experiments and 9 rotational experiments were conducted. The combinations of the levels of factors employed in each experiment are summarized in Tables 4 and 5 .

Table 5 Factor-level combinations for the rotational experiments

\begin{tabular}{cll}
\hline Experiment no. & $\begin{array}{l}\text { Factor A: } \\
\text { extrusion/rotary table } \\
\text { ratio (level) }\end{array}$ & $\begin{array}{l}\text { Factor B: } \\
\text { extrusion } \\
\text { radius (level) }\end{array}$ \\
\hline 1 & 1 & 1 \\
2 & 1 & 2 \\
3 & 1 & 3 \\
4 & 2 & 1 \\
5 & 2 & 2 \\
6 & 2 & 3 \\
7 & 3 & 1 \\
8 & 3 & 2 \\
9 & 3 & 3 \\
\hline
\end{tabular}

\section{Implementation}

\subsection{Experimental setup}

In the experimental apparatus used in this study, the extruder head was fixed in space. The movement of the scanner head was emulated via the use of either a conveyor belt (emulating the movement in a linear path) or a circular rotational table (emulating the movement in a curved path). More specifically, the experimental setup consisted of the following parts:

1. Extruder. The extruder was filled with the concrete AM material and was responsible for the material extrusion.

2. Conveyor belt system. It simulated the movement of the scanner head in the linear experiment.

3. Rotary table. It simulated the movement of the scanner head in the rotational experiment.

Therefore, under-extrusion, over-extrusion, or 1:1 extrusion could be achieved by matching the extrusion speed to the linear speed of each experimental device (conveyor belt, rotary table). More specifically, when the linear speed of the conveyor belt or of the rotary table (in a specific radius) was higher than the extrusion speed, the phenomenon of underextrusion occurred, whereas in the opposite case, overextrusion occurred. When the two speeds were matched, 1:1 extrusion occurred.

Consequently, the experimental apparatus was capable of representing a cement-based AM machine in order to identify the effect and significance of the process parameters (extrusion speed, ratio, and radius under which the extrusion takes place) on the quality and cohesion of single layer paths. Figure 3 illustrates the CAD design of the implemented AM experimental apparatus; in Figs. 4 and 5, images of the

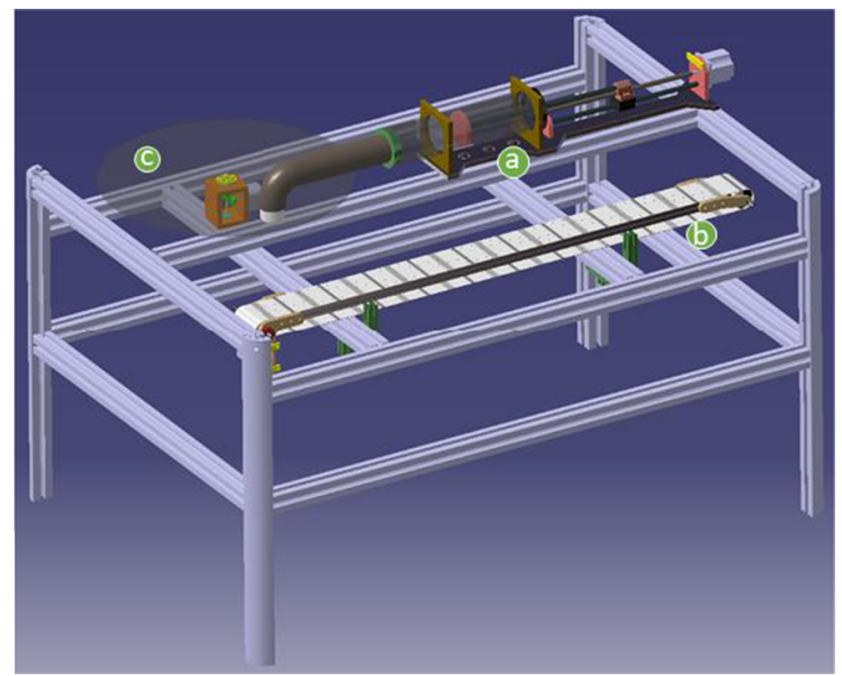

Fig. 3 Design of the experimental apparatus. a Extruder system. b Conveyor belt. c Rotary table 
Fig. 4 Image of the experimental apparatus. a Extruder system. b Rotary table. c Controller

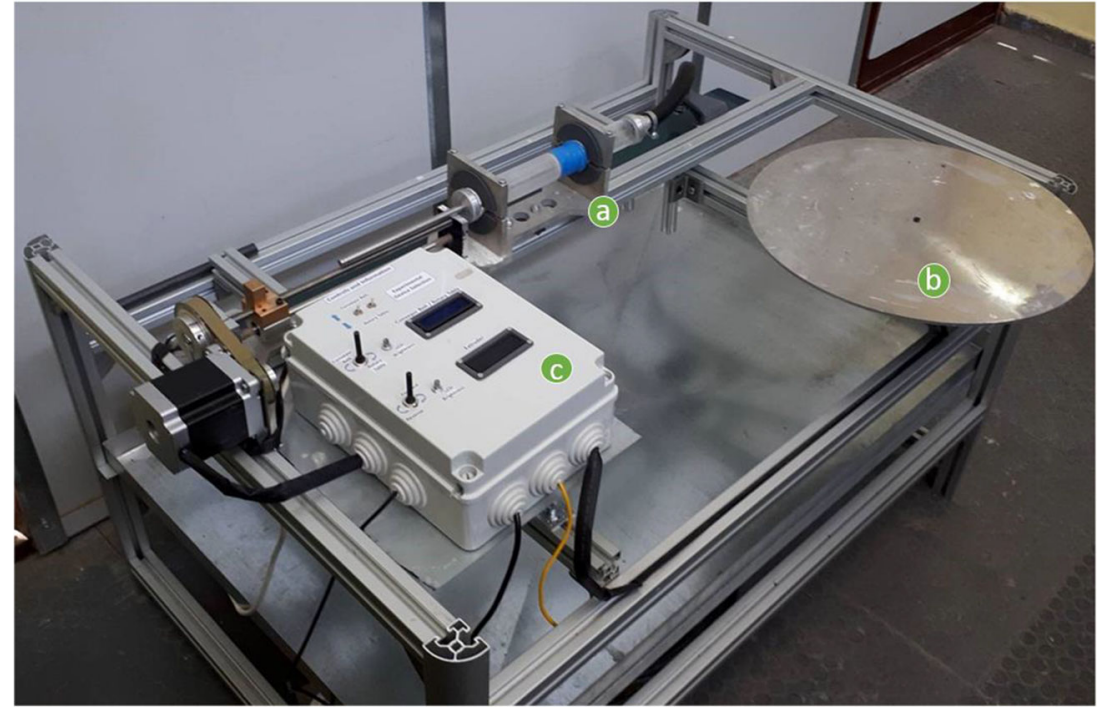

experimental device are presented. The operational range of the experimental apparatus is listed in Table 6, whereas Table 7 summarizes certain key dimensions.

Stepper motors were selected owing to their ability to accurately maintain their rotational speed regardless of the applied load, under the conditions that the required power is supplied and that the applied load is within the operational range of the motor. For the control of the speed of the motors, a commercial micro-controller was used. A potentiometer was used for adjusting the value of the rotational speed, which was visualized on an LCD screen. A schematic of the connections

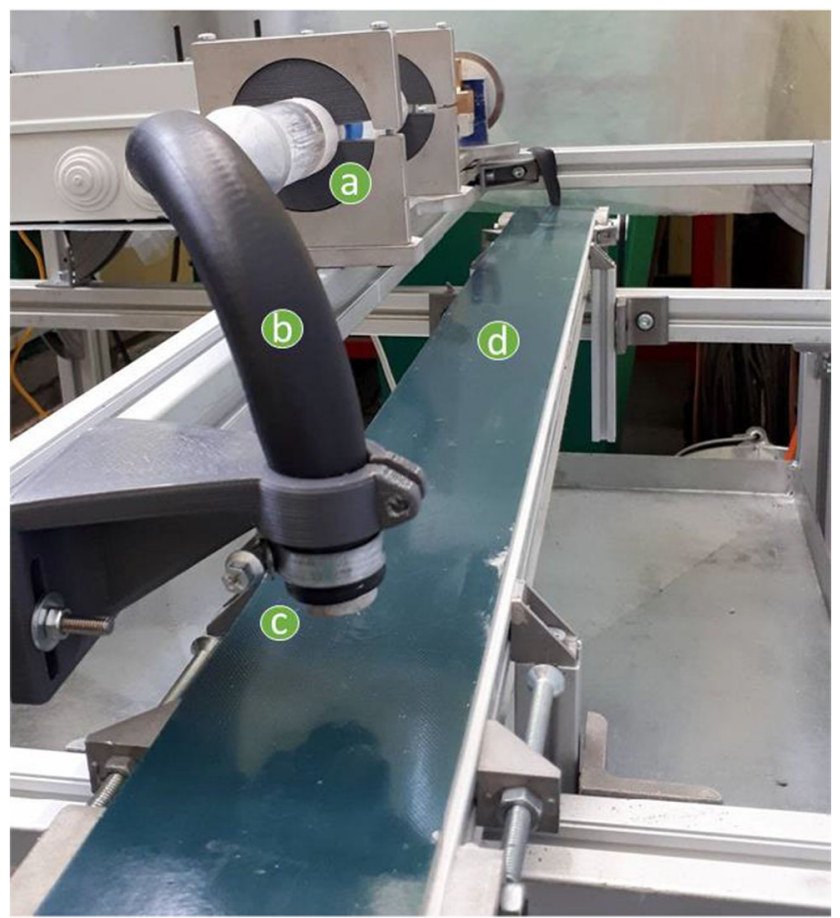

Fig. 5 Image of the experimental apparatus. a Extruder system. b Pipe. c Nozzle. d Conveyor belt of the controller, potentiometer, motor, and motor driver is depicted in Fig. 6.

The motor driver that was employed was capable of microstepping; this enabled the accurate control of the motor and ensured fluid and continuous movement, even at very low values of the rotational speed. This is important because the material mix was sensitive to vibrations, which had a negative effect on the cohesion of the mix. Details of the components of the controller are listed in Table 8 .

\subsection{Material}

Cement-based materials used in AM applications are subject to a complex set of technical requirements; the most important of these requirements is based on the workability of the materials [17]. Workability is a measure of how easy or difficult it is to place, consolidate, and finish a concrete mix [32]. Therefore, cement-based materials that are suitable for AM must be both sufficiently fluid - to ensure an easier flow in the AM machine and through the nozzle - and sufficiently

Table 6 Operational range of the experimental apparatus: (a) 1:2 transmission, (b) 2:1 transmission

\begin{tabular}{ll}
\hline Parameter & Value \\
\hline Max force (measured at the slider) & $\begin{array}{l}\text { a. } \sim 170 \mathrm{~kg}(1667 \mathrm{~N}) \\
\text { b. } \sim 640 \mathrm{~kg}(6276 \mathrm{~N})\end{array}$ \\
Max pressure & a. $\sim 18.8 \mathrm{bar}\left(2.88 \times 10^{6} \mathrm{~N} / \mathrm{m}^{2}\right)$ \\
& b. $\sim 66.5 \mathrm{bar}\left(6.65 \times 10^{6} \mathrm{~N} / \mathrm{m}^{2}\right)$ \\
Max piston speed & a. $28.5 \mathrm{~mm} / \mathrm{s}$ \\
& b. $7.15 \mathrm{~mm} / \mathrm{s}$ \\
$\begin{array}{ll}\text { Max extrusion speed at the nozzle } & \text { a. } 254 \mathrm{~mm} / \mathrm{s} \\
\text { (round nozzle) } & \text { b. } 63.5 \mathrm{~mm} / \mathrm{s}\end{array}$ \\
\hline
\end{tabular}


Table 7 Dimensions of the experimental apparatus

\begin{tabular}{ll}
\hline Dimension & Value \\
\hline Overall & $740 \mathrm{~mm} \times 120 \mathrm{~mm} \times 120 \mathrm{~mm}$ \\
Nozzle dimensions (diameter) & $11.28 \mathrm{~mm}$ \\
Volume & $0.27 \mathrm{~L}$ \\
Conveyor belt length & $2077 \mathrm{~mm}$ \\
Conveyor belt width & $80 \mathrm{~mm}$ \\
Rotary table diameter & $500 \mathrm{~mm}$ \\
\hline
\end{tabular}

firm - to maintain their shape after extrusion and to sustain the weight of the next layers $[10,17]$.

The material used in this study was the $\mathrm{C} 60$ viscosity modifying admixture (VMA)-based formulation; the material properties and testing can be found in a previous work [17]. The mixing was performed as follows: a material batch was prepared and was left for $5 \mathrm{~min}$ in the mixer to simulate the pumping time that would be required in a real-scale application. Next, the final additive, a VMA, was added and incorporated through a very short mixing procedure (30 $s$ of mixing at a moderate speed) [17].

The proper mixing, consistency, and uniformity of the material properties in between the different experiments was ensured by measuring the shear strength of each material batch using a shear testing vane [33]. This procedure has been described by Elaty et al. [34]; according to them, the shear vane test is capable of measuring the workability of fresh concrete. The mechanical properties of the material and of the test parts [17] have also been verified. Specifically, concerning the early age properties of the mix, its shear stress has been measured at $1.90 \mathrm{kPa}$ and $2.50 \mathrm{kPa}$ after 5 and $10 \mathrm{~min}$ of mixing respectively. The strength of the printed parts has been found to be $340 \mathrm{kPa}$ (240 min after the mixing), also verified in [17, 24].
Table 8 Controller-component details

\begin{tabular}{|c|c|c|}
\hline \multirow[t]{2}{*}{ Type of component } & \multicolumn{2}{|l|}{ Details } \\
\hline & Extruder & $\begin{array}{l}\text { Conveyor } \\
\text { belt/rotational } \\
\text { table }\end{array}$ \\
\hline $\begin{array}{l}\text { Control unit } \\
\text { (micro-controller) }\end{array}$ & \multicolumn{2}{|c|}{ Arduino Uno } \\
\hline Motor driver & Wantai DQ860MA & Wantai DQ542MA \\
\hline Motor & $\begin{array}{l}\text { Wantai Stepper } \\
\text { Motor } \\
\text { 85BYGH450D-008 }\end{array}$ & $\begin{array}{l}\text { Lin Engineering } \\
\text { 5718L-01P }\end{array}$ \\
\hline Power supply & \multicolumn{2}{|c|}{$60 \mathrm{~V}, 5.8 \mathrm{~A}$} \\
\hline
\end{tabular}

\section{Results and discussion}

To analyze the results, an analysis of variance (ANOVA) was performed. The selected objective function (signal-to-noise (SN) ratio) was the-larger-the better because the larger the value of the PCQM would be, the better the quality and the consistency of the test part was [31]. The optimum level for a factor was the one that would yield the highest SN value within the experimental region. Figure 7 shows the plot for the $\mathrm{SN}$ ratios of the linear experiment. The optimum level values of the two factors are (i) extrusion/conveyor ratio = 1.2 (level 4) and (ii) extrusion speed $=12 \mathrm{~mm} / \mathrm{s}$ and $15 \mathrm{~mm} /$ $\mathrm{s}$ (both levels 1 and 2). However, it may be observed that the effect of the different levels of factor B is not significant because the SN value is maintained fairly constant for the different values of extrusion speed.

A cross-section view and a top view of five experimental samples are illustrated in Figs. 8 and 9, respectively. The quality is the highest in test part (b) and is closely followed by that of (a); part (c) is still of acceptable

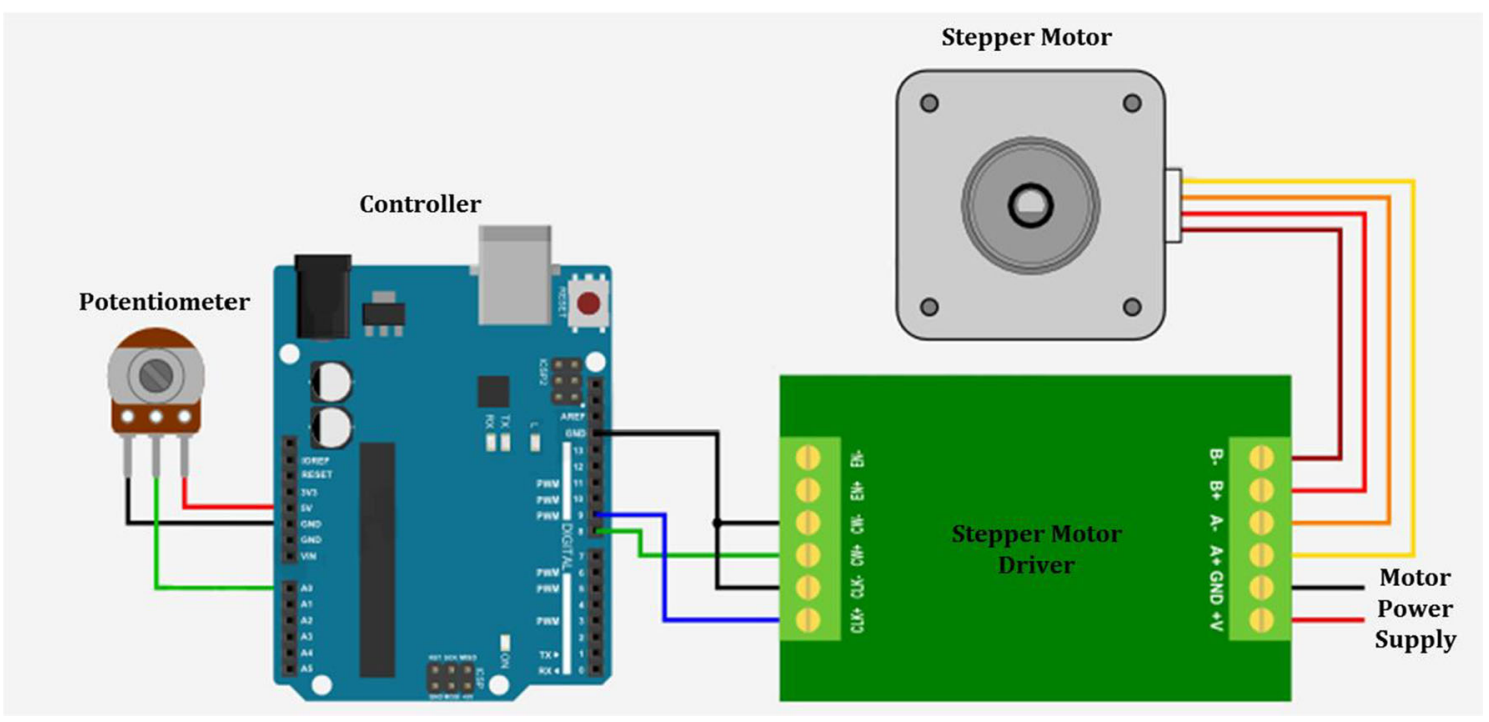

Fig. 6 Connections between the controller, potentiometer, stepper motor, and driver 
Fig. 7 Main-effects plot for SN ratios for the linear-extrusion experiment

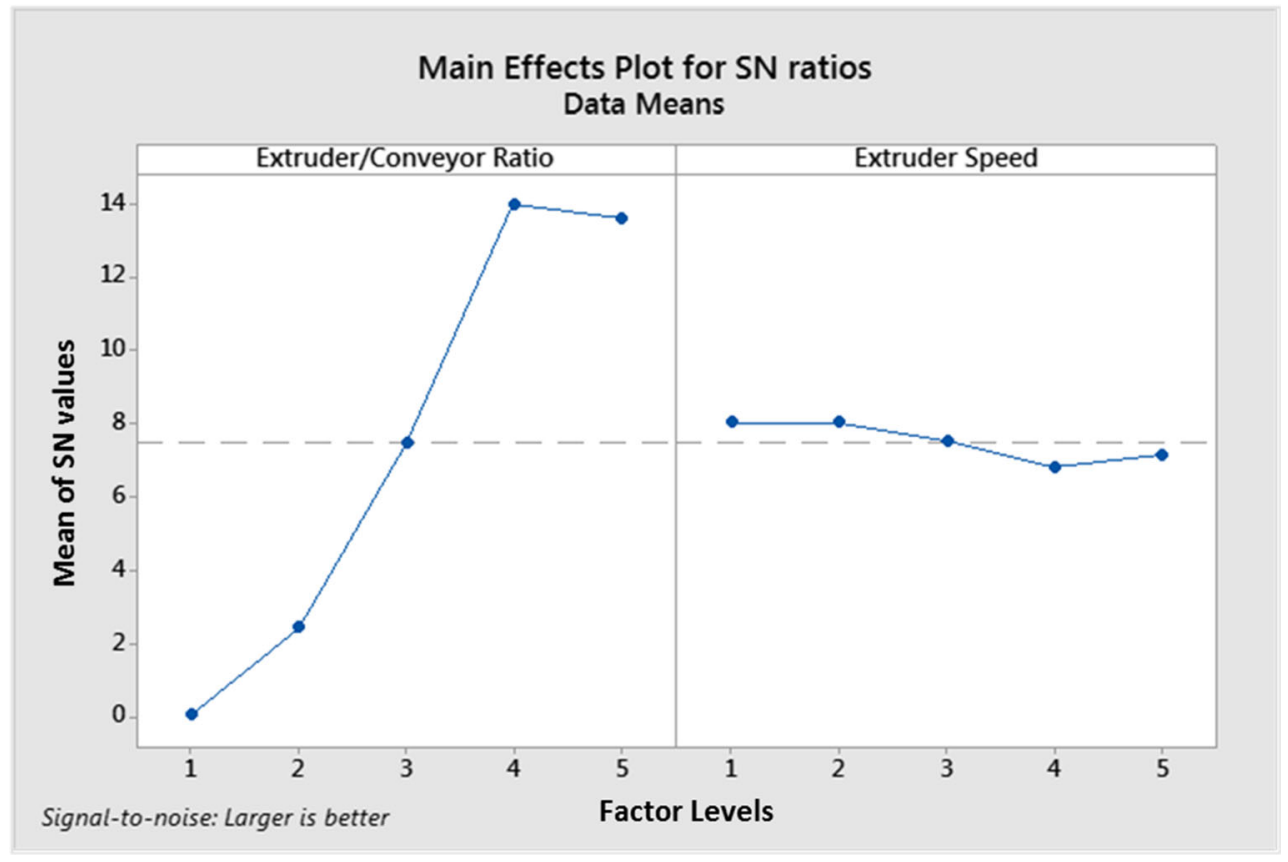

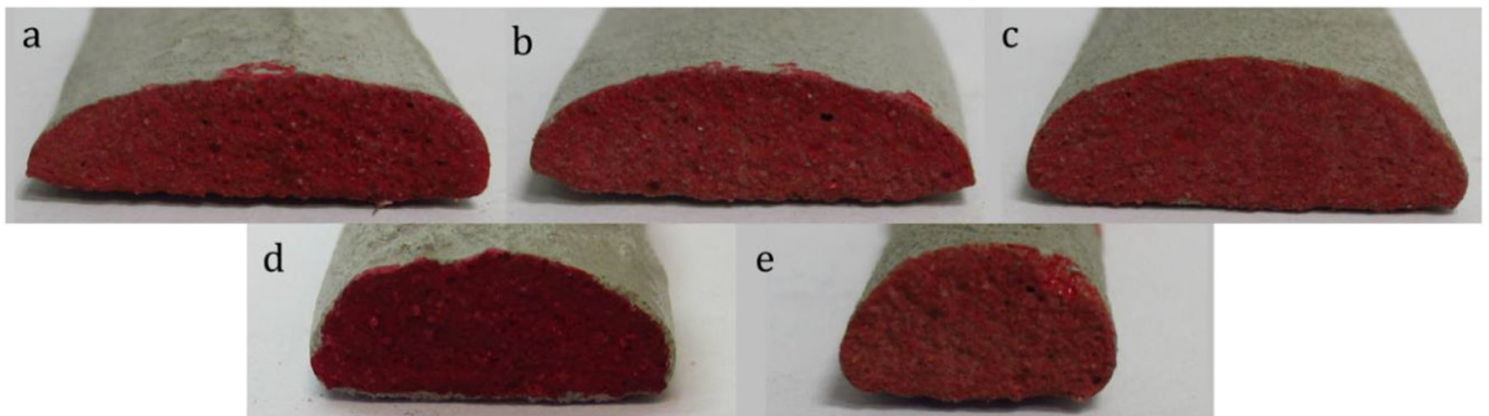

Fig. 8 Linear-extrusion experiment test samples (section view)

quality. Parts (d) and (e) can be considered to be of unacceptable quality. More details about the process parameters and the PCQM of the test parts are listed in Table 9. By comparing the cross-sections from part (a) to part (e), it may be observed that the cross-section area decreases; this is attributed to the fact that the ratio from test part (a) to test part (e) decreases as well.
Considering the experimental results, the speed ratios of the extrusion speed and scanner head that lead to the production of test parts of acceptable quality are:

$2>$ ratio $_{\text {acceptable }}>0.8$

These results have also been validated through ANOVA (Table 10), in which the $P$ value of factor A (ratio) was found
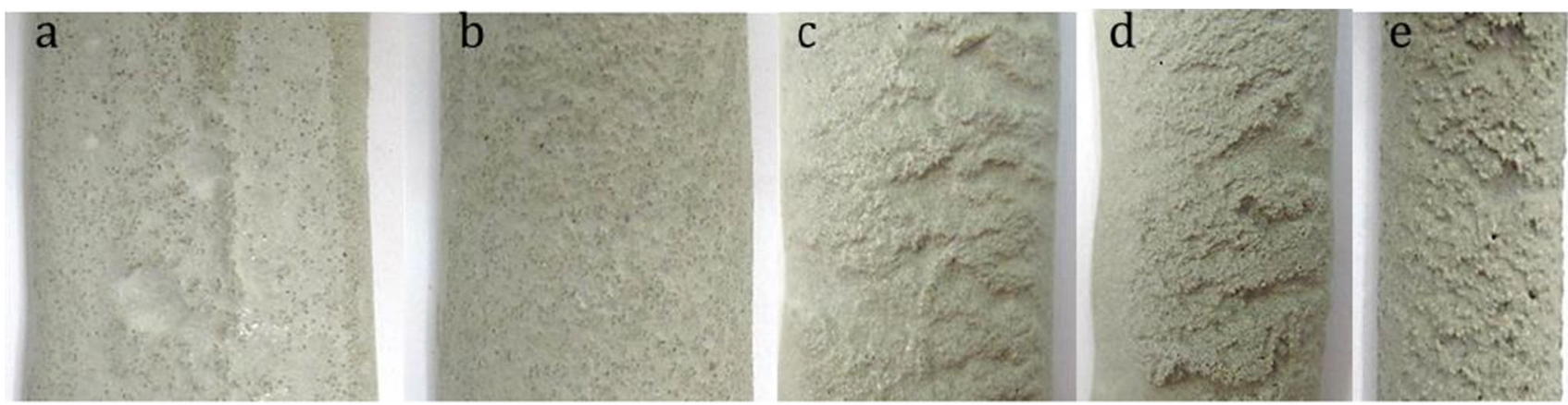

Fig. 9 Linear-extrusion experiment test samples (top view) 
Table 9 Process parameters and PCQM of the test samples in Figs. 8 and 9

\begin{tabular}{llllll}
\hline $\begin{array}{l}\text { Test } \\
\text { part }\end{array}$ & $\begin{array}{l}\text { Experiment } \\
\text { no. (as per } \\
\text { Table 4) }\end{array}$ & $\begin{array}{l}\text { Factor A: } \\
\text { extrusion/ } \\
\text { conveyor ratio } \\
\text { (level) }\end{array}$ & $\begin{array}{l}\text { Factor B: } \\
\text { extrusion } \\
\text { speed } \\
\text { (level) }\end{array}$ & PCQM & $\begin{array}{l}\text { Summary } \\
\text { statistic, } \\
\text { S/N }\end{array}$ \\
\hline a & 25 & 5 & 5 & 4 & 12.04 \\
b & 20 & 4 & 5 & 5 & 13.98 \\
c & 15 & 3 & 5 & 3 & 9.54 \\
d & 7 & 2 & 2 & 2 & 6.02 \\
e & 5 & 1 & 5 & 1 & 0.00 \\
\hline
\end{tabular}

Table 10 ANOVA table for the linear experiments

\begin{tabular}{lrllrrr}
\hline $\begin{array}{l}\text { ANOVA } \\
\text { Source of variation }\end{array}$ & \multicolumn{1}{c}{$\mathrm{SS}$} & df & MS & \multicolumn{1}{l}{$F$} & $P$ value & $F_{\text {crit. }}$ \\
\hline Factor A (ratio) & 70.644 & 4 & 17.667 & 95.459 & $5.94 \mathrm{E}-11$ & 3.007 \\
$\begin{array}{l}\text { Factor B (extrusion } \\
\quad \text { speed) }\end{array}$ & 0.244 & 4 & 0.060 & 0.324 & 0.857 & 3.007 \\
Error & & & & & & \\
Total & 2.967 & 16 & 0.185 & & & \\
\hline
\end{tabular}

$S S$ is the sum of squares, $d f$ are the degrees of freedom, and $M S$ is the mean square

to be significantly lower than the value used for $\alpha$; this indicates a significant difference among the levels of this factor. On the contrary, the $P$ value of factor B (extrusion speed) is significantly higher than the value used for $\alpha$, indicating that there is no significant difference between the levels of this factor. This is reflected in the very unbalanced $95.67 \%$ and $0.91 \%$ contributions of factors A and B, respectively, which was calculated using the total sum of squares and the sum of squares due to the two factors (A, B). The sum of squares is equal to $4.19 \%$ owing to the presence of error. The results of the $F$ test are equivalent as well.

The same procedure has been followed for the rotational tests as well. Figure 10 illustrates the plot for the $\mathrm{S} / \mathrm{N}$ ratios. According to the plot of Fig. 10 and by selecting the level that corresponds to the maximum value of each factor, the optimum level values are (i) extrusion/rotary table ratio $=1.27$ (level 3) and (ii) radius $=200 \mathrm{~mm}$ (level 3).

A cross-section view and a top view of four experimental samples are shown in Figs.11 and 12, respectively. The ratio used for the test parts decreases from test part (a) to test part (d); this is reflected in the area of their cross-section, which also decreases. The quality is the highest in test parts (a) and (b), followed by (c). Part (d) can be considered to be of unacceptable quality. More details about the process parameters and PCQM of the test parts are listed in Table 11.

These results have also been validated through ANOVA (Table 12), in which the $P$ value of factor A was found to be significantly lower than the $\alpha$ value, which indicates a significant difference among the levels of this factor. The $P$ value of factor $\mathrm{B}$ is significantly higher than that of factor A and is close to the value used for $\alpha$; however, it is lower than the value used for $\alpha$, indicating that there is a somewhat significant difference between the levels of this factor. The same is reflected in the $F$ test.

Using the total sum of squares and the sum of squares due to the two factors (A, B), the responsibility (\%) of each variation factor can be estimated. The extrusion/ rotary table speed (factor A) is an important factor that
Fig. 10 Main-effects plot for the $\mathrm{SN}$ ratios of the rotational experiment

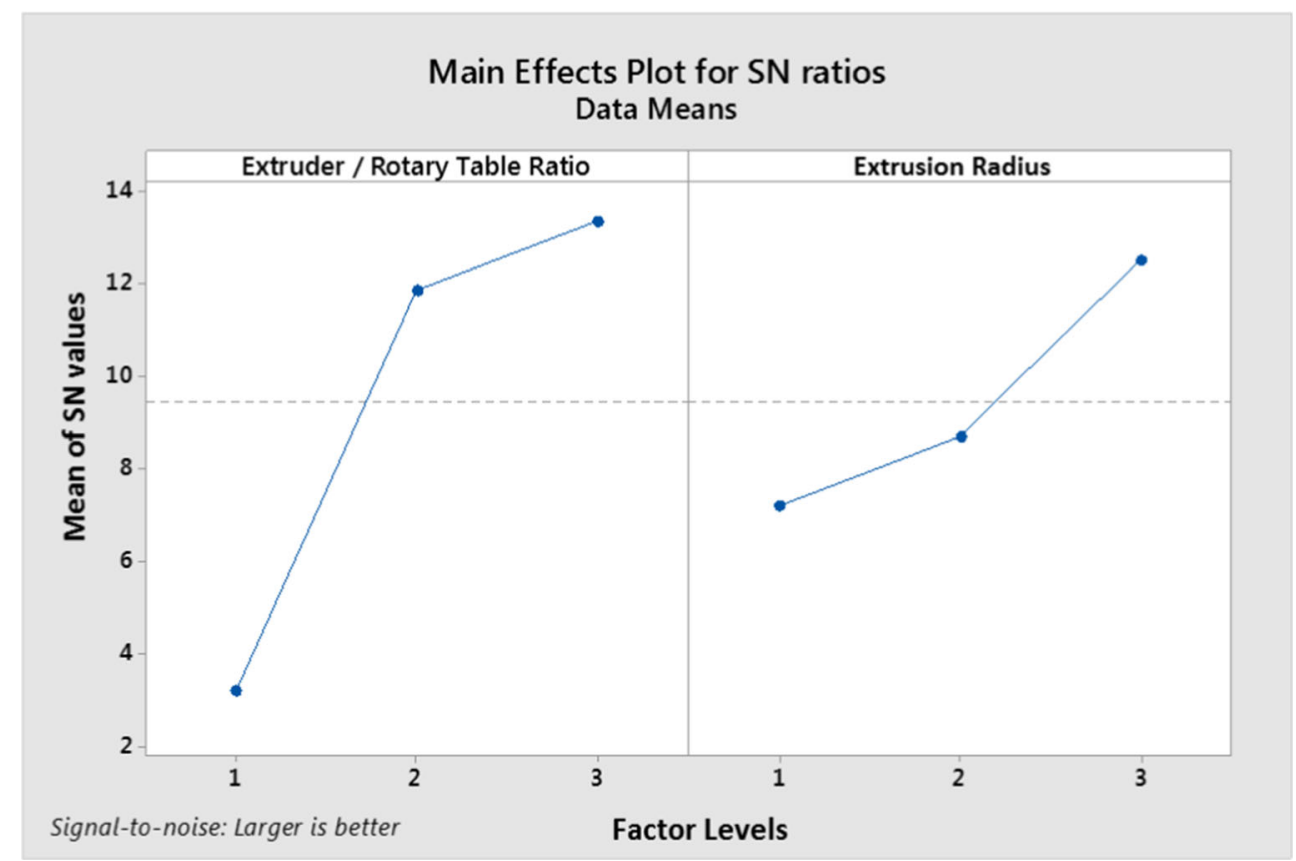


Fig. 11 Rotational-extrusion experiment test samples (section view)

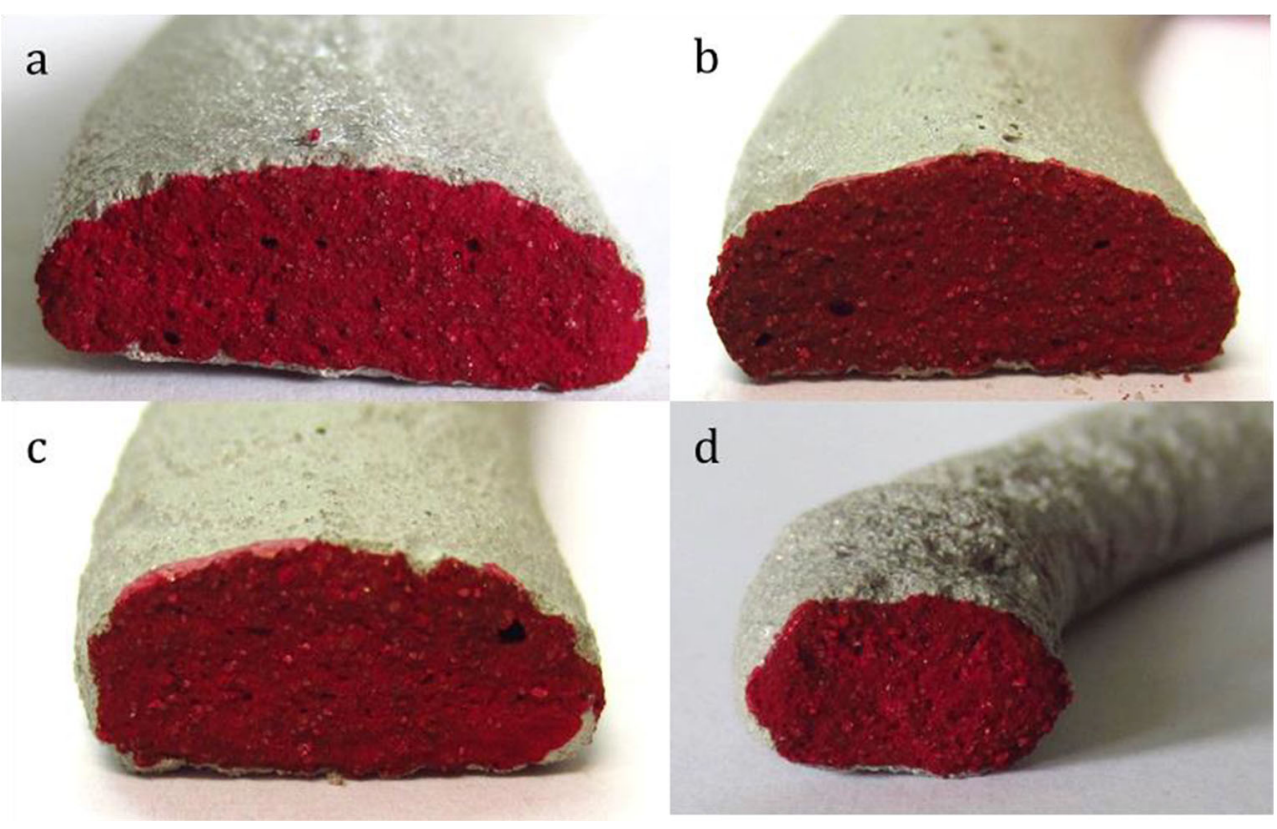

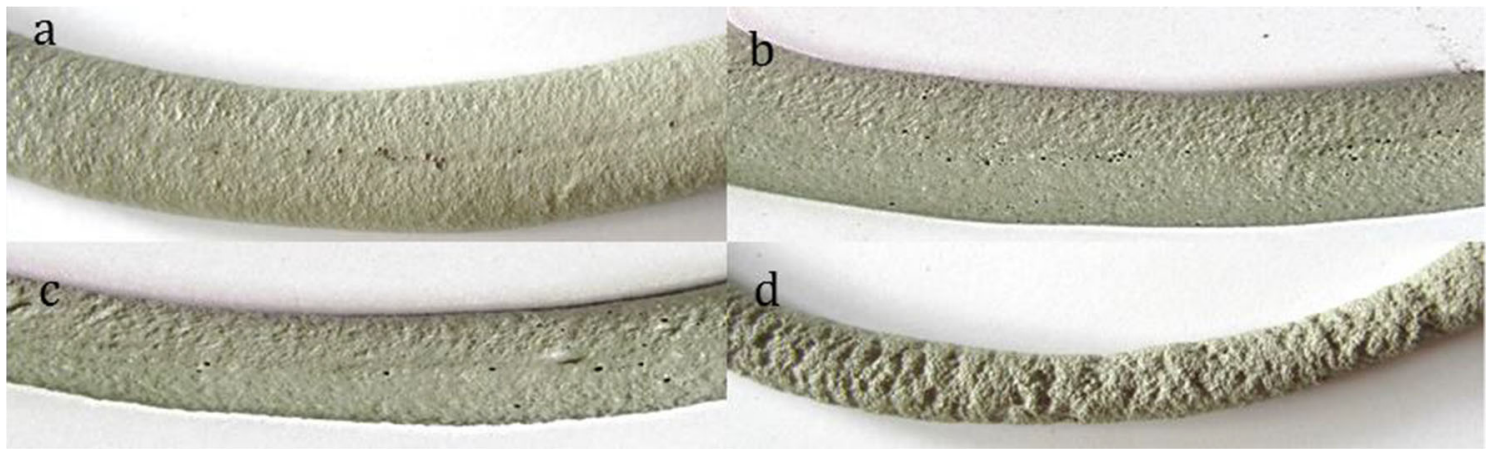

Fig. 12 Rotational-extrusion experiment test samples (top view)

significantly affects the quality and consistency of the test part (73.58\% responsibility). The radius is also important (factor B), but not equally so ( $26.03 \%$ responsibility). The sum of squares due to error was $5.49 \%$. The high significance of the speed ratio was expected, whereas the significance of the radius was approximately one-third of that of the speed ratio. Therefore, the ratio is the most

Table 11 Process parameters and PCQM of the test sample in Figs. 11 and 12

\begin{tabular}{llllll}
\hline $\begin{array}{l}\text { Test } \\
\text { part }\end{array}$ & $\begin{array}{l}\text { Experiment } \\
\text { no. (as per } \\
\text { Table 5) }\end{array}$ & $\begin{array}{l}\text { Factor A: } \\
\text { extrusion/ } \\
\text { conveyor ratio } \\
\text { (level) }\end{array}$ & $\begin{array}{l}\text { Factor B: } \\
\text { extrusion } \\
\text { radius } \\
\text { (level) }\end{array}$ & $\begin{array}{l}\text { Average } \\
\text { PCQM } \\
\text { (level) }\end{array}$ & $\begin{array}{l}\text { Summary } \\
\text { statistic, } \\
\text { S/N }\end{array}$ \\
\hline a & 9 & 3 & 3 & 5 & 13.98 \\
b & 5 & 2 & 2 & 4 & 12.04 \\
c & 3 & 1 & 3 & 3 & 9.54 \\
d & 1 & 1 & 1 & 1 & 0.00 \\
\hline
\end{tabular}

important factor; however, the curvature also affects the part quality and cannot be neglected.

An important observation based on the curved-extrusion experiments is that the quality and consistency of the outer side of the part tended to be lower than those of the inner side of the part. This was attributed to the fact that the phenomenon of underextrusion is more intense on the outer side of the part than on the centerline, and even less so on the inner side. Based on this observation, the following equation was developed:

ratio $_{\mathrm{loc}}=\frac{v_{\mathrm{ex}}}{\omega R_{\mathrm{loc}}}$

where ratio ${ }_{\text {loc }}$ is the local ratio, $R_{\mathrm{loc}}$ is the local radius, and $\omega$ is the rotational speed of the rotary table. Therefore, to calculate the ratio on the outer side of the part, ratio ${ }_{\text {outer }}$ the $R_{\mathrm{loc}}$ value that corresponds to the outer side of the test part should be used.

To demonstrate the above, two cases are presented; more specifically, Fig. 13 illustrates the difference in quality and consistency between the inner and the outer side of different test parts. The ratio calculated on the centerline of part no. 2 is 
Table 12 ANOVA table for the rotational experiments

\begin{tabular}{lrllrll}
\hline $\begin{array}{l}\text { ANOVA } \\
\text { Source of variation }\end{array}$ & \multicolumn{1}{l}{ SS } & df & \multicolumn{1}{l}{ MS } & \multicolumn{1}{l}{$F$} & $P$ value & $F_{\text {crit. }}$ \\
\hline Factor A (ratio) & 14.889 & 2 & 7.444 & 26.8 & 0.004823 & 6.944 \\
Factor B (radius) & 4.222 & 2 & 2.111 & 7.6 & 0.043403 & 6.944 \\
Error & 1.111 & 4 & 0.2778 & & & \\
Total & 20.222 & 8 & & & & \\
\hline
\end{tabular}

0.8 . However, the outer ratio of the part (which was calculated using Eq. (3)) is 0.75. This value is below the threshold of 0.8, which is the value that had been defined as the limit over which successful parts are created. More details on ratio calculations on the inner side, the outer side, and the centerline of the parts of Fig. 13 are summarized in Table 13.

This equation can provide a good indication on whether a part will be successful: by ensuring that the local ratio of the outer side of a part is higher than the critical ratio, successful curved parts of any radius can be manufactured.

\section{Conclusions}

In this experimental study, an experimental apparatus was designed and constructed to investigate the significance of important process parameters on the quality of parts manufactured via cement-based AM. Moreover, the

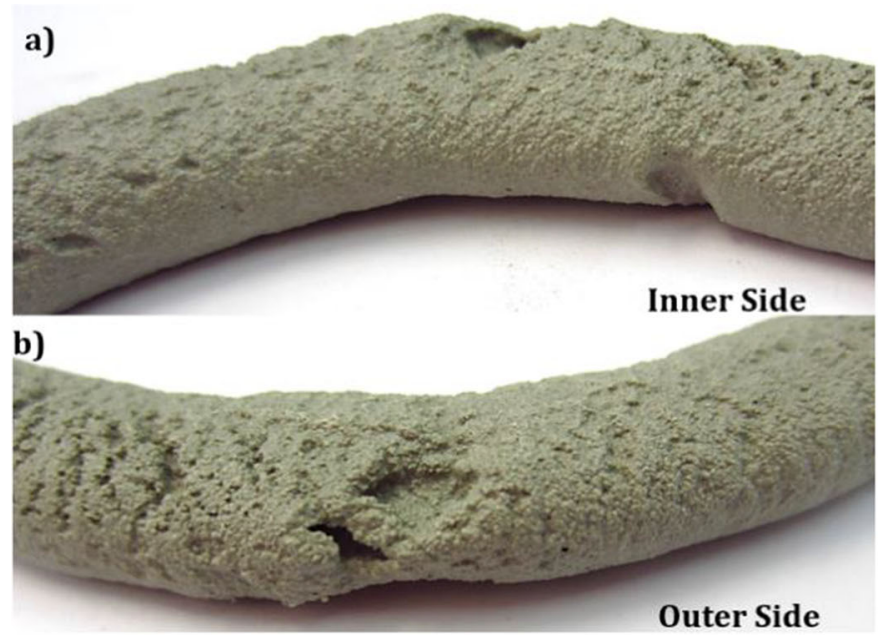

Taguchi and ANOVA methods were applied. It was found that in linear extrusion, the part quality depended solely on the ratio of the extrusion/conveyor belt speeds. This was also indicated by the ANOVA results: $95.67 \%$ contribution for the extrusion/conveyor ratio and $0.91 \%$ for the extrusion speed. The value range of the ratios that yielded an acceptable part quality was $2>$ ratio $_{\text {acceptable }}>$ 0.8 . Using ratios below 0.8 resulted in uneven surfaces because the material was stretched, thus being irregularly deformed. In curved extrusion, the effect of the ratio was the most important parameter $(73.58 \%)$. However, the radius under which the extrusion took place also played an important role $(26.03 \%)$. Consequently, in real applications, not only the ratio but also the curvature should be considered in the process of achieving acceptable part quality. However, it was observed that during curved extrusion, it was the outer side of the part that demonstrated issues in part quality and cohesion. Therefore, by calculating the ratio on the outer side of the part and by maintaining it within acceptable values ( ratio $_{\text {acceptable }}>0.8$ ), parts of acceptable quality and consistency can be created for any curvature. Thus, only one parameter has to be considered, namely the outer ratio, which simplifies the control procedure.

By following the proposed path-width control strategy, increased part quality can be achieved. The corresponding optimal parameters might differ for a different material mix; however, the same approach can be implemented to

c)

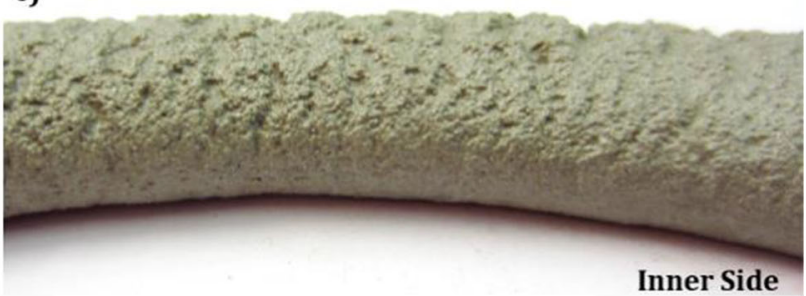

d)

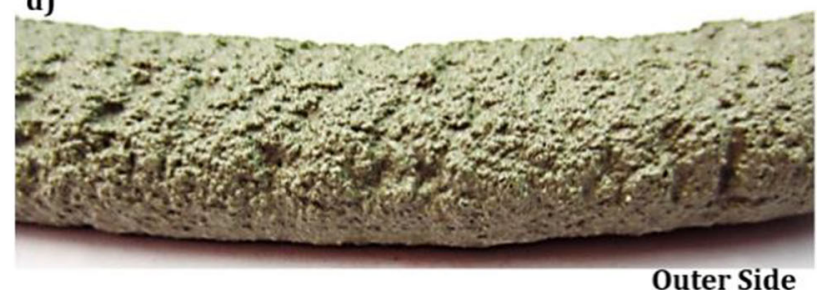

Fig. 13 Difference in quality and consistency between the inner and outer side of test part. a Inner side of part no. 1. b Outer side of part no. 1. c Inner side of part no. 2. d Outer side of part no. 2. Part no. 1: ratio level 1, radius level 1. Part no. 2: ratio level 1, radius level 2

Table 13 Values of inner and outer ratio and the resulting differences in the inner and outer PCQM for rotational extrusion for different radius values

\begin{tabular}{ccccccccc}
\hline Experiment no. (as per Table 5) & Width (mm) & Radius (mm) & Ratio & Ratio $_{\text {inner }}$ & Ratio $_{\text {outer }}$ & PCQM (centerline) & PCQM inner & PCQM outer \\
\hline 1 & 12.4 & 50 & 0.76 & 0.87 & 0.68 & 1 & 2 & 1 \\
2 & 12.7 & 100 & 0.80 & 0.85 & 0.75 & 1 & 3 & 1 \\
\hline
\end{tabular}


define them. Therefore, by identifying the value range of acceptable ratios for linear extrusion and by utilizing Eq. (3), the manufacturing of high-quality parts using different cement-based materials for both linear and curved paths can be achieved.

Acknowledgments This work is under the framework of the EU Project HINDCON.

Funding information This project has been partially funded from the European Union's Horizon 2020 research and innovation program under grant agreement no. 723611 .

Open Access This article is licensed under a Creative Commons Attribution 4.0 International License, which permits use, sharing, adaptation, distribution and reproduction in any medium or format, as long as you give appropriate credit to the original author(s) and the source, provide a link to the Creative Commons licence, and indicate if changes were made. The images or other third party material in this article are included in the article's Creative Commons licence, unless indicated otherwise in a credit line to the material. If material is not included in the article's Creative Commons licence and your intended use is not permitted by statutory regulation or exceeds the permitted use, you will need to obtain permission directly from the copyright holder. To view a copy of this licence, visit http://creativecommons.org/licenses/by/4.0/.

\section{References}

1. European Commission Report, The European construction sector, a global partner, (2016). Available online at: https:/ec.europa.eu/ growth/content/european-construction-sector-global-partner-0_en. Accessed 21/06/2018

2. Union I, Communication from the Commission to the European Parliament, the Council, the European Economic and Social Committee and the Committee of the Regions. Brussels, (2014). http://ww.w.xploit-eu.com/pdfs/Europe\% 202020\%20Flagship\%20Initiative\%20INNOVATION.pdf. Accessed 31/01/2019

3. Ghaffar SH, Corker J, Fan M (2018) Additive manufacturing technology and its implementation in construction as an eco-innovative solution. Autom Constr 93:1-11. https://doi.org/10.1016/j.autcon. 2018.05.005

4. Wu P, Wang J, Wang X (2016) A critical review of the use of 3-D printing in the construction industry. Autom Constr 68:21-31. https://doi.org/10.1016/j.autcon.2016.04.005

5. ISO/ASTM Standard, standard terminology for additive manufacturing technologies, ISO/ASTM52900 - 15.http://www. astm.org/cgi-bin/resolver.cgi?ISOASTM52900-15. Accessed 31/ $01 / 2019$

6. Foteinopoulos P, Papacharalampopoulos A, Stavropoulos P (2018) On thermal modeling of additive manufacturing processes. CIRP J Manuf Sci Technol 20:66-83. https://doi.org/10.1016/j.cirpj.2017. 09.007

7. Stavropoulos P, Foteinopoulos P (2018) Modelling of additive manufacturing processes: a review and classification. Manufactur Rev 5:7-33. https://doi.org/10.1051/mfreview/ 2017014

8. Bikas H, Lianos AK, Stavropoulos P (2019) A design framework for additive manufacturing. Int $\mathrm{J}$ Adv Manuf Technol 103:1-15. https://doi.org/10.1007/s00170-01903627-z
9. Thomas D (2016) Costs, benefits, and adoption of additive manufacturing: a supply chain perspective. Int J Adv Manuf Technol 85(5-8):1857-1876. https://doi.org/10.1007/s00170-0157973-6

10. Liang F, Liang Y (2014) Study on the status quo and problems of 3D printed buildings in China. Global J HumanSocial Sci 14(5):7-10 https://socialscienceresearch.org/index. php/GJHSS/article/view/1317. Accessed 31/01/2019

11. Chryssolouris G (2006) Manufacturing systems: theory and practice. New York, Springer-Verlag

12. Bikas H, Stavropoulos P, Chryssolouris G (2016) Additive manufacturing methods and modelling approaches: a critical review. Int J Adv Manuf Technol 83(1-4):389-405. https://doi.org/ 10.1007/s00170-015-7576-2

13. Bos F, Wolfs R, Ahmed Z, Salet T (2016) Additive manufacturing of concrete in construction: potentials and challenges of $3 \mathrm{D}$ concrete printing. Virt Phys Prototyp 11:209-225. https://doi.org/10. 1080/17452759.2016.1209867

14. Lowke D, Dini E, Perrot A, Weger D, Gehlen C, Dillenburger B (2018) Particle-bed 3D printing in concrete construction-possibilities and challenges. Cem Concr Res 112:50-65. https://doi.org/10.1016/j.cemconres.2018.05.018

15. Le TT, Austin SA, Lim S, Buswell RA, Gibb AG, Thorpe T (2012) Mix design and fresh properties for high-performance printing concrete. Mater Struct 45(8):1221-1232. https://doi.org/10.1617/ s11527-012-9828-Z

16. Gosselin C, Duballet R, Roux P, Gaudillière N, Dirrenberger J, Morel P (2016) Large scale 3D printing of ultra-high performance concrete - a new processing route for architect and builder. Mat Des 100:102-109. https://doi.org/10.1016/j. matdes.2016.03.097

17. Esnault V, Labyad A, Chantin M, Toussaint F (2018) Experience in online modification of rheology and strength acquisition of $3 \mathrm{D}$ printable mortars, RILEM International Conference on Concrete and Digital Fabrication, Springer Cham 24-38. https://doi.org/10. 1007/978-3-319-99519-9 31

18. Hinczewski C, Corbel S, Chartier T (1998) Stereolithography for the fabrication of ceramic three-dimensional parts. Rapid Prototyp J 4(3):104-111. https://doi.org/10.1108/ 13552549810222867

19. Khoshnevis B, Bukkapatnam S, Kown H, Saito J (2001) Experimental investigation of contour crafting using ceramics materials. Rapid Prototyp J 7(1):32-41. https://doi.org/10.1108/ 13552540110365144

20. Lim S, Buswell RA, Le TT, Austin SA, Gibb AGF, Thorpe T (2012) Developments in construction-scale additive manufacturing processes. Autom Constr 21:262-268. https://doi.org/10.1016/j. autcon.2011.06.010

21. Salet TAM, Ahmed ZY, Bos FP, Laagland HLM (2018) Design of a $3 \mathrm{D}$ printed concrete bridge by testing. Virt Phys Prototyp 13:222-236. https://doi.org/10.1080/ 17452759.2018.1476064

22. Panda B, Paul SC, Mohamed NA, Tay YWD, Tan MJ (2018) Measurement of tensile bond strength of 3D printed geopolymer mortar. Measurement 113:108-116. https://doi.org/10.1016/j. measurement.2017.08.051

23. Flatt RJ, Wangler $\mathrm{T}$ (2018) Editorial for special issue on digital concrete. Cem Concr Res 112:1-4. https://doi.org/10.1016/j. cemconres.2018.07.007

24. HINDCON EU Project (2016) Hybrid INDustrial CONstruction through a 3D printing "all-in-one" machine for large-scale advanced manufacturing and building processes https://cordis.europa.eu/project/rcn/205443/factsheet/ en 
25. Bird RB, Dai GC, Yarusso BJ (1983) The rheology and flow of viscoplastic materials. Rev Chem Eng 1(1):1-70. https://doi.org/10. 1515/revce-1983-0102

26. Zhang L, Greenfield ML (2007) Relaxation time, diffusion, and viscosity analysis of model asphalt systems using molecular simulation. J Chem Phys 127(19):1-13. https://doi.org/10.1063/1. 2799189

27. Jayasree C, Gettu R (2008) Experimental study of the flow behaviour of superplasticized cement paste. Mater Struct 41(9):15811593. https://doi.org/10.1617/s11527-008-9350-5

28. Roussel N (2007) Rheology of fresh concrete: from measurements to predictions of casting processes. Mater Struct 40(10):1001-1012. https://doi.org/10.1617/s11527-007-9313-2

29. Cyr M, Legrand C, Mouret M (2000) Study of the shear thickening effect of superplasticizers on the rheological behaviour of cement pastes containing or not mineral additives. Cem Concr Res 30(9):1477-1483. https://doi.org/10.1016/ S0008-8846(00)00330-6

30. Papo A, Piani L (2004) Effect of various superplasticizers on the rheological properties of Portland cement pastes. Cem Concr Res
34(11):2097-2101. https://doi.org/10.1016/j.cemconres.2004.03. 017

31. Phadke MS (1989) Quality engineering using robust design. River, Prentice Hall PTR Upper Saddle

32. Kosmatka SH, Panarese WC (1998) Design and control of concrete mixtures, Skokie, IL: Portland Cement Association, 1988

33. Pilcon Hand Vane Tester SL815, Impact Test Equipment Ltd. http:// www.impact-test.co.uk/docs/SL815_HB.pdf. Accessed 31/01/ 2019

34. Elaty MAA, Ghazy MF (2012) Flow properties of fresh concrete by using modified geotechnical vane shear test. Hous Build Natl Res Cen J 8(3):159-169. https://doi.org/ 10.1016/j.hbrcj.2012.07.001

Publisher's note Springer Nature remains neutral with regard to jurisdictional claims in published maps and institutional affiliations. 